Pediatric

Neurosurgery
Pediatr Neurosurg 2013;49:186

DOI: $10.1159 / 000360368$
Received: February 3, 2014

Accepted: February 5, 2014

Published online: March 27, 2014

\title{
Comment on the Paper by Abbo et al. Entitled 'Delayed Diagnosis of Neurologic Bladder following Spinal Cord Injury without Radiologic Abnormality'
}

The paper by Abbo et al. [1] highlights the difficulty of detecting spinal cord injuries in young children, specifically when injury to other organ systems may hinder the neurological examination. It is not clear if this was a spinal cord injury without radiologic abnormality since the imaging was not done early in the course of the injury. A spinal cord lesion that may have been detected on imaging may have been missed. Therefore, this report highlights the flaw in not performing detailed, e.g. MRI, imaging, early in the course of a high-velocity mechanism. If there is not a high index of suspension, potentially catastrophic complications such as bladder rupture can occur.

\section{Reference}

Abbo O, Mouttalib S, Kaissi M, Sauvat F, Accadbled F, Harper L: Delayed diagnosis of neurologic bladder following spinal cord injury without radiologic abnormality. Pediatr Neurosurg DOI: 10.1159/000360402.
Timothy M. George, MD

Dell Children's Medical Center of Central Texas

Chief of Pediatric Neurosurgery/Neuroscience, University of Texas at Austin

1301 Barbara Jordan Blvd., Suite 307, Austin, TX 78723 (USA)

E-Mail tmgeorge@seton.org 